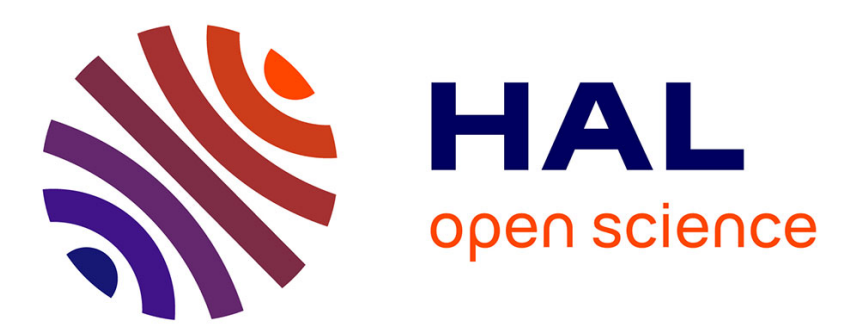

\title{
An approach to diagnose local and collaborative supply chain processes
}

\author{
Matthieu Lauras, Hervé Pingaud, Jacques Lamothe
}

\section{To cite this version:}

Matthieu Lauras, Hervé Pingaud, Jacques Lamothe. An approach to diagnose local and collaborative supply chain processes. International Journal of Logistics Systems and Management, 2009, 5 (3/4), 10.1504/IJLSM.2009.022503 . hal-01777894

\section{HAL Id: hal-01777894 \\ https://hal.science/hal-01777894}

Submitted on 6 Nov 2018

HAL is a multi-disciplinary open access archive for the deposit and dissemination of scientific research documents, whether they are published or not. The documents may come from teaching and research institutions in France or abroad, or from public or private research centers.
L'archive ouverte pluridisciplinaire HAL, est destinée au dépôt et à la diffusion de documents scientifiques de niveau recherche, publiés ou non, émanant des établissements d'enseignement et de recherche français ou étrangers, des laboratoires publics ou privés. 


\title{
An approach to diagnose local and collaborative supply chain processes
}

\section{Matthieu Lauras*, Hervé Pingaud and Jacques Lamothe}

\author{
Department of Industrial Engineering, \\ Université de Toulouse - Mines d'Albi, \\ Campus Jarlard, route de Teillet, 81013 Albi, France \\ E-mail: lauras@enstimac.fr \\ E-mail: pingaud@enstimac.fr \\ E-mail: lamothe@enstimac.fr \\ *Corresponding author
}

\begin{abstract}
It is often really difficult to capture and exploit knowledge about a given supply chain, covering all types of flows and business processes. Supply chain managers have frequently to make diagnosis and need realistic representations of their supply chain. We work on a methodology that tries to help them in this way. First, a framework is designed to capture information on multiple dimensions of supply chain, from structural to operational aspects. Then, a data analysis approach is detailed and put into practice to explain the differences between current and ideal entities, so that progress actions can be identified.
\end{abstract}

Keywords: supply chain management; SCM; framework; diagnosis; processes; data analysis; cooperation.

\footnotetext{
Biographical notes: Matthieu Lauras was Supply Chain Project Manager in a pharmaceutical company from 2001 to 2005. After this experience he joined the Industrial Engineering Department of the Ecole des Mines d'Albi as an Assistant Professor. His works mostly focus on performance management and integration of supply chain processes. All his researches concern as well the industrial sector as the humanitarian sector. He has published several papers in journals and international conferences in the area of supply chain management.
}

Hervé Pingaud is a full Professor at the Industrial Engineering Department of the Ecole des Mines d'Albi. His main research interests are informational systems, project and risks management and cooperative networks. All his works are based on a business process approach. He is responsible for the national French working group on business process and interoperability. He has published tens of technical papers in journals.

Jacques Lamothe is an Associate Professor of Supply Chain Management. He works at the Industrial Engineering Department of the Ecole des Mines 
d'Albi. He manages the Supply Chain Research axis of the Department. His research mainly concerns the design and control of supply chains. He publishes many papers on Supply Chain Management in European Journal of Operation Research, International Journal of Production Research, International Journal of Business Performance Management and Journal of Integrated Computer-aided Engineering.

\section{Introduction}

Supply Chain Management (SCM) plays a major role in increasing performance and competitiveness of companies. Simchi-Levi et al. (2003) define SCM as

\footnotetext{
"a set of approaches utilised to efficiently integrate suppliers, warehouses, and stores, so that merchandise is produced and distributed at the right quantities, to the right locations, and at the right time, in order to minimise systemwide costs while satisfying service level requirements."
}

SCM is made up of two main areas (according to Stadtler, 2005):

- network integration: management of cooperation between entities of the network and development of their ability to work together

- network coordination: management of each entity of the supply chain, in order to control flows effectively, and achieve the supply chain goals.

Beamon (1999) and Gunasekaran et al. (2004) explain that important supply chain features have been ignored by the control theory. Performance control, and more specifically cost control, are limited due to the composite nature of the Supply Chain (SC). Several authors have studied recently these network based organisations with this perspective (Aviv, 2001; Dudek and Stadtler, 2004; Villareal et al., 2005). SCM not only tries to control the performance of individual predefined processes, as well as expected collaborative processes, it also has to deal with continuous improvement of these processes in order to maintain them at a high level of integration. So, the network is not a frozen architecture: each node has sufficient autonomy to adapt its own processes, and could behave like an inductor of transformation.

Cooperative game theory put forward the weak balance between shared and individual objectives of partners as an explanation of these adaptation needs. In consequence, keeping control at a satisfying level involves an ability to supervise individual and collaborative processes, and eventually to adapt some of the performance variables.

In this paper, a methodology is proposed that allows a SCM to build a realistic representation of the system and to make diagnosis using this representation.

In a first part, a literature study identifies fundamental components which are relevant to get a supply chain diagnosis. The objective is to define a framework based on questionnaires that helps supply chain managers to make investigations. Integration and coordination metrics are defined on the basis of answers made to the set of relevant questions. Data are collected by meeting actors in their workplaces, or produces through appropriate links to the information system (especially through requests to databases). It provides a large amount of well structured supply chain data. 
Then, in a second part, the relevance of our approach is restricted to a two-stage supply chain with a centralised control structure. Individual entities are supposed to be linked to a unique central node as it is usually the case in worldwide companies that distributes the same kind of goods all over the world. Each partner of such a supply chain can have some similarities with others, even if long distance separate them. So, we propose to use multivariate data analysis methods in order to extract information from the large spectrum of variables that characterise the broad and spread population of entities. The ability to discriminate groups of entities with similar processes is very useful for the central and main control entity. We will show these effects on an industrial case study.

\section{From supply chain's fundamentals to a diagnosis framework}

Because we need to understand the operating modes of the supply chain, we have to collect and organise data. However, due to the problem of size, direct observation without methodology is fastidious and inefficient on a large scale SC. We consider naturally the question of how to prepare and make an investigation. Investigation supports have not been a subject of discussion in the scientific literature on SCM. If there are widely known reference frameworks: SCOR model or Global EVALOG, for example, it seems that they are mainly used as audit supports rather than diagnosis supports. We mean that they try to validate what is supposed to be a correct execution with respect to best practices or standards established before. By contrast, diagnosis will not refer to predefined proposals. Diagnosis just relates to existing operating modes without any reference to a preset frame, and focused on a set of elementary questions: what? when? where? who? with which? how? with what? and why?

The concept of framework can be used for a SCM diagnosis. It will concentrate on the structure of subjects that should be treated in order to design a particular questionnaire starting from a generic and well defined database of questions. We will not detail here the generic questionnaire. In the following, we discuss only supply chain topics that have to be unified in order to define a structured framework. The topics will be presented by sections into the framework. If local process models are quite easy to capture, it is not the case for collaborative processes. This last point will be more specifically studied.

\subsection{Flows of entities through a supply chain}

Various approaches and definitions (Stadtler and Kilger, 2000; Mentzer et al., 2001; Arnold and Chapman, 2004) consider SC as co-ordinated system that manages flows. Cooper and Ellram (1991), for example, define the SCM as "an integrative philosophy to manage the total flow of a distribution channel from the supplier to the ultimate user".

These flows are financial, informational, or physical flows. A reference framework for supply chain diagnosis must provide a definition of flows (informational, physical and financial), to qualify the objects to be managed in the supply chain ('What?').

As can be seen in Table 1, the physical flows are classified depending whether they are upstream flows relative to suppliers, internal flows relative to an intermediate node, or rather downstream ones relative to customers. Descriptive variables that will be quantified or qualified are listed for each type of flows. 
Table 1 Referential framework to diagnose supply chain physical flows

\begin{tabular}{|c|c|c|}
\hline Sections & Sub-sections & Main topics \\
\hline \multicolumn{3}{|c|}{ Physical flows } \\
\hline \multicolumn{3}{|c|}{ The upstream flows } \\
\hline & 1 Receipted units & Units, weight, palets, orders, receipts. . . \\
\hline & 2 Stocks & $\begin{array}{l}\text { Raw material average inventory, } \\
\text { max \& min inventory (palets, units)... }\end{array}$ \\
\hline & 3 Staff & Kind of contracts (permanent, temporary... ) \\
\hline & 4 Product numbers & $\begin{array}{l}\text { Number of references, by brand, by kind } \\
\text { of products... }\end{array}$ \\
\hline & 5 Suppliers & Number of suppliers, repartition by channel. . . \\
\hline \multicolumn{3}{|c|}{ The internal flows } \\
\hline & 6 Produced units & Units, weight, fabrication orders, ... \\
\hline & 7 Stocks & $\begin{array}{l}\text { Average in-process inventory, } \\
\text { min \& max inventory (palets, units)... }\end{array}$ \\
\hline & 8 Staff & Kind of contracts (permanent, temporary... ) \\
\hline & 9 Product numbers & $\begin{array}{l}\text { Number of references, by brand, by } \\
\text { kind of products... }\end{array}$ \\
\hline & 10 Sub-contractors & $\begin{array}{l}\text { Number of sub-contractors, repartition } \\
\text { by channel... }\end{array}$ \\
\hline \multicolumn{3}{|c|}{ The downstream flows } \\
\hline & 11 Distributed units & Orders, picks, shipments, order-lines, weight. . . \\
\hline & 12 Stocks & $\begin{array}{l}\text { Average available inventory, } \\
\text { min \& max inventory (palets, units)... }\end{array}$ \\
\hline & 13 Staff & Kind of contracts (permanent, temporary... ) \\
\hline & 14 Product numbers & $\begin{array}{l}\text { Number of references, by brand, by } \\
\text { kind of products... }\end{array}$ \\
\hline & 15 Third-party log. & Number of 3rd party, repartition of the flows. . \\
\hline & 16 Customers & $\begin{array}{l}\text { Number of customers, repartition of } \\
\text { sales and units per channel... }\end{array}$ \\
\hline
\end{tabular}

\subsection{Key functions of a supply chain}

Handfield and Nichols (2002) or Simchi-Levi et al. (2003) consider that without a foundation of effective organisational relationships among supply chain partners, efforts to manage the flow of materials or information across the supply chain are likely to be unsuccessful. A sequence of agreements between entities - of one or more companies, from the first of the suppliers to the consumers - has to be existed. Many models have been developed using this approach (Kearney, 1994; Croxton et al., 2001; Supply Chain Council, 2004; Chen and Paulraj, 2004). At a macroscopic level, all these authors state clearly that a supply chain is just a collection of interrelated functions: Procurement, Manufacturing, Distribution, Global planning, Marketing and Sales. Naturally, processes can be thought as particular detailed representations of such macro functions. Inspiring by Chopra and Meindl (2003) proposal, we could split them into three categories: functions that transform physical flows following a logic of stream (supply, manufacture, distribute), functions that concern the customer relations (sale and marketing) and then, functions that control the activities (planning). The ultimate objective is to understand how the supply chain performance is achieved through the combination of these functions (transverse processes). Heikkila (2002) 
identifies two main categories of related study: works on the chain structure, and studies of the network behaviour. With a similar approach, Stadtler (2005) proposes two fundamental concepts. On the one hand, SCM 'coordination' is defined like a type of business process management: planning and scheduling decisions are made to control flows. It is based both on Information Technologies, and on business process models. On the other hand, SCM 'integration' refers more specially to business process design at the level of the network. For example, choice of network entities, and of selected activities are typically included in this second category.

As an evidence, the functions appears to be common denominators of these two facets of SCM. Stadtler (2005) identifies three main components for:

- the supply chain coordination: processes, Information Technologies and planning methods

- the supply chain integration: partners characteristics, supply chain network design and management.

\subsection{Key components of SCM 'coordination'}

\subsubsection{The processes}

In an integrative supply chain strategy, business processes create value for customers. But these processes reach beyond the boundaries of the firm by drawing suppliers and customers into the value creation process (Vickery et al., 2003). Handfield and Nichols (2002) say that organisations must have a detailed understanding of current processes to embark in the promising world of SCM. A process is a suite of activities that uses resources to allow the transformation of inputs to outputs. Whatever the function under study, this is a problem to identify how its is realised, by executing the given set of activities, or even the set of processes. Hammer and Champy (1993) were among the first to recognise a process as a set of activities directed towards the production of a result representing a value for the customer. Croxton et al. (2001) and Manthou et al. (2005) affirm that SCM is increasingly being recognised as the integration of key business processes across the supply chain. The concept of value for the customer supposes that a performance can be measured, and requires at the outset a commitment on each activity. This is absolutely necessary for the process management in order to define continuous improvement. The representation of processes is often done using a cartography, that can be seen as a map on which process interfaces are shown.

\subsubsection{Information Technologies (IT)}

Providing decision-makers within the supply chain the right information, in the necessary format, and in a timely manner is a major challenge. Particularly, to success this challenge could be viewed as a major strategy to counter the so-called 'bullwhip effect' (Lee et al., 2000). To do that, supply chains use Information Technologies (IT) that include all the techniques of collection, storage, treatment and data dissemination whatever they are. It's a fact, IT transform the way exchange-related activities in supply chain are performed, and the nature of linkages between them (Palmer and Griffith, 1998). Progress made in the few decades in data-processing has deeply upset the management of companies and supply chains in terms of modularity, accessibility and inclusiveness (Upton and McAfee, 2000). The main difficulty clearly consists in making individual information systems becoming collaborative information systems. 
Lee et al. (2000), Cachon and Fisher (2000) and Vickery et al. (2003) propose some good practices when using IT, that summarises clearly all the difficulties of the exercise even if they appear as really simple principles. Firstly, the value carried by an exchanged data should be meaningful for its user, this is the right information at the right place (in order to avoid problems such as grossly inaccurate demand forecast, low capacity utilisation, excessive inventory, long lead times and delivery frequencies, and poor customer service). Secondly, the quality of an information is contextual, the situation to which the information is attached has an effect on its value, and any evolution of the situation can require an actualisation of the information. Thirdly, an ideal system should span all functions and organisations throughout the entire supply chain in order to enhance collaboration and coordinate activities (Handfield and Nichols, 2002; Chronéer, 2004). So a SCM diagnosis must consider IT maturity in the SCM. This implies three aspects: information systems architecture; information viability (quality with respect to time); and relevance of information.

\subsubsection{Planning}

The planning process concerns each function of the supply chain. A part of operations management is always done inside the company with limited transparency for the supply chain. Nevertheless, a global planning function also exists in order to centralise and integrate some key decisions. The basic idea, as proposed by Supply Chain Council (2004), is to distinguish global decisions (same for all entities) from local ones. The planning process seeks to make suitable decisions in order to satisfy customer's demand, while using resources in the best way (Dudek, 2004). Planning is split into several time horizons depending on degrees of smoothness in the analysis of the demands compared to the capacities. This decomposition provides some chance to do what is expected in terms of resource allocations, and 'guarantee' that the assigned orders will be completely satisfied (Chopra and Meindl, 2003). Arnold and Chapman (2004) note several properties necessary to implement a planning process:

- among them, the various steps of a planning shall be necessarily supported by specific methods - formal or not, structured or not

- to be efficient, planning rules must be defined to solve conflicts, and find a balance between loads and capacities

- finally, control of budget is crucial in order to approximate real financial possibilities, and to help in making decision (investments, cost controls).

\subsubsection{Synthesis}

We add a new table in addition to Table 1 inside the framework to diagnose the SCM coordination of each function and explain "when? where? who? what? how? with what? and why?" of the local operations.

\subsection{Key components of SCM 'integration'}

\subsubsection{Partners}

A partner is an actor, internal or external, individual or collective, specialised or general practitioner who works in a collaborative process (Poirier and Reiter, 1996). A partner 
can be a distributor, a subcontractor, a provider or a supplier. A collaboration between partners is a mutual ongoing relationship that involves a high level of trust, commitment over a period of time, long-term contracts, joint conflict resolution, and the sharing of information, risks and rewards (Ellram, 1991). Poirier and Reiter (1996) explain that the choice of a partner must be based on customer requirements. The added value analysis of the potential partner competencies compared to existing competencies in the supply chain (Stadtler and Kilger, 2000) is a main criteria for selection. A potential partner must prove its ability to meet expressed requirements of the supply chain. This can be achieved by its competencies, knowledge, resources or know-how. Vickery et al. (2003) underline that partners work together to ensure high product quality and low costs, with benefit sharing. Moreover, because the customer requirements could evolve, it is often necessary to check the adequacy of partner contributions to actual demand. It should be stated that this process is not limited to simple economic criteria, but must also integrate all kind of capabilities (Arnold and Chapman, 2004).

\subsubsection{Management of a supply chain network}

A supply chain gathers various entities which are not under the same legal heading. The question arising then is how the network is controlled. Very often, a natural leader appears (Stadtler and Kilger, 2000) for various reasons such as financial capacity; knowhow on products or processes; value added to the product. According to the same authors, decisions taken by the leadership of this central entity will be accepted by other entities of the supply chain without discussion. In other cases, the supply chain can be managed by a steering committee. It is composed of representatives of the supply chain and is managed according to predefined collective rules and processes (Villareal et al., 2005). (Benton and Maloni, 2005) stress a particular risk associated to management of the supply chain network. They explain that some dominant firms may behave with opportunity, in such cases performing individually will always be preferred to partnership, and submitting to a supply chain partner is accepted only when the balance of power makes it necessary. As for any management activity, the network management activity can be analysed through:

- its environmental constraints: laws, regulations, benchmark and best practices

- its internal history: individual entities lay out, their own culture, procedures and the supply chain as a whole

- the evaluation of performance and the continuous improvement.

Performance evaluation is not itself sufficient: it is only one of the links in management process. In order to control a system, position, target and resources must be known at the same moment.

\subsubsection{Nature and organisation of the collaborative network}

Williamson (1985) characterises two extremes forms of governance: perfectly competitive markets and vertically integrated hierarchies. Chen and Paulraj (2004) indicate that an intermediate form of governance is the network. Network firms are characterised by strong linkages between supply chain members with low levels of 
vertical integration (Rigatto et al., 2005). A reference frame of collaborative states has been proposed in (Lauras, 2004). This proposal showed that the collaborative components could be characterised by four fundamental elements:

- defining a common objective, object of the agreement, beyond simple individual interests: combining competences for the achievement of a particular project, supporting a continuous activity

- going beyond individual limits: bringing solutions to the intrinsic limits of each entity is necessary (forces and weaknesses of each entity to achieve the common objective)

- qualifying methods of agreement: forms of concretisation, formal or not, of cooperation (contracts, commitments and constraints, perimeters and horizons)

- having a common risk management: locating the options to be taken and anticipating the risks associated with operations in order to identify consequences and responsibilities if an event occurs.

In a logistic contract Lauras (2004) identifies two main factors that distinguish various states of agreement:

- The objects shared by partners: are they data, data processing or both of them?

- The temporality of cooperation: the cooperation can be made either occasionally on demand, or frequently with objects exchanged with a predefined process, and lastly can be made continuously with objects regularly shared?

\subsubsection{Synthesis}

In addition to Tables 1 and 2, another table could be defined inside the framework to diagnose the SCM integration of each function and explain when? where? who? what? with which? how? and why? of collaborative operations (Table 3).

\subsection{Global architecture to structure a SCM Diagnosis}

From all these elements (cartography of flows, function analysis: coordination and integration), we can define a global architecture that allows to make a relevant SCM diagnosis (Figure 1).

We can remark that we have added a branch to this architecture in order to qualify the relationship between each node of the supply chain and the environment (culture of the company, history, local regulation, etc.). Actually, these dimensions influence directly the supply chain's behaviour.

\section{Formulation of a data analysis problem for supply chain diagnosis}

A study of supply chain starts with observations made on the field by means of exchanges with actors representative of the various entities, and using our framework. Once this collection realised, rough information is aggregated for all (or some of) the entities. These data could be broken down into quantitative elements (flows, states of 
inventory or capacity), but also into qualitative elements broken down into functions: Supplying, Manufacturing, Distributing, Sales, Marketing, Planning. Then, in order to extract 'the essential' information, statistical tools, and more particularly data analysis tools, offer the means of classifying the whole of the criteria by explaining the differences between the entities.

Table 2 Referential framework to diagnose local processes

\begin{tabular}{|c|c|c|}
\hline Sections & Sub-sections & Main topics \\
\hline \multirow{2}{*}{\multicolumn{3}{|c|}{$\begin{array}{l}\text { SCM coordination } \\
\text { Processes }\end{array}$}} \\
\hline & & \\
\hline \multirow{5}{*}{ Processes } & 1 Activities & $\begin{array}{l}\text { Added Value, primary operation, } \\
\text { temporality... }\end{array}$ \\
\hline & 2 Resources & $\begin{array}{l}\text { Human resources, Financial resources, } \\
\text { material resources... }\end{array}$ \\
\hline & 3 Inputs / Outputs & $\begin{array}{l}\text { Object, Results of the process, } \\
\text { periodicity... }\end{array}$ \\
\hline & 4 Controls & $\begin{array}{l}\text { Objectives of the activity, link with the } \\
\text { strategy, periodicity... }\end{array}$ \\
\hline & 5 Local performance & $\begin{array}{l}\text { Dashboards, objectives, exhaustiveness, } \\
\text { interest. . }\end{array}$ \\
\hline \multicolumn{3}{|r|}{ (1) } \\
\hline & 6 Informational systems & $\begin{array}{l}\text { Softwares, needs adequacy, } \\
\text { architecture... }\end{array}$ \\
\hline & 7 Information reliability & $\begin{array}{l}\text { Updating of data, documentations, } \\
\text { relevance of use... }\end{array}$ \\
\hline & 8 Adequacy with strategy & Needs adequacy, limits, projects. . . \\
\hline \multicolumn{3}{|c|}{ Global planning } \\
\hline & 9 Budgetary management & $\begin{array}{l}\text { Investments, fixed asset turnover, } \\
\text { reporting, costs reduction... }\end{array}$ \\
\hline & 10 Demand Management & $\begin{array}{l}\text { Load / capacity analysis, product family, } \\
\text { horizon / frequency... }\end{array}$ \\
\hline & 11 Methods and tools & Procedure, formulation, precision... \\
\hline & 12 Sources & Exhaustiveness, relevance, update... \\
\hline & 13 Decision levers & Priorities, action levers, horizon. .. \\
\hline
\end{tabular}

\subsection{Hypothesis and principles}

In this study, we consider a supply chain defined as a simple twofold tree; so that the entities (i.e., the nodes) can be classified by level. It is assumed that entities of a given level may have the same role (added value for final customers), the same local functions and can be brought together into a single category. It should be normal that they work with similar processes. However sue to a lot of factors (including culture, market, history, ...), it is not the case. Here, data analysis is used to help in the characterisation of roles and in the classification of processes. From another point of view, managers need to evaluate the gap to best practices. Virtual 'best practices' entities are therefore added to the data: experts answer their questionnaire considering how such 'best practices' could be implemented. Consequently, data analysis is used to enlighten the most significant topics that explain the gap to the 'best practices'. 
Table 3 Referential framework to diagnose cooperative processes

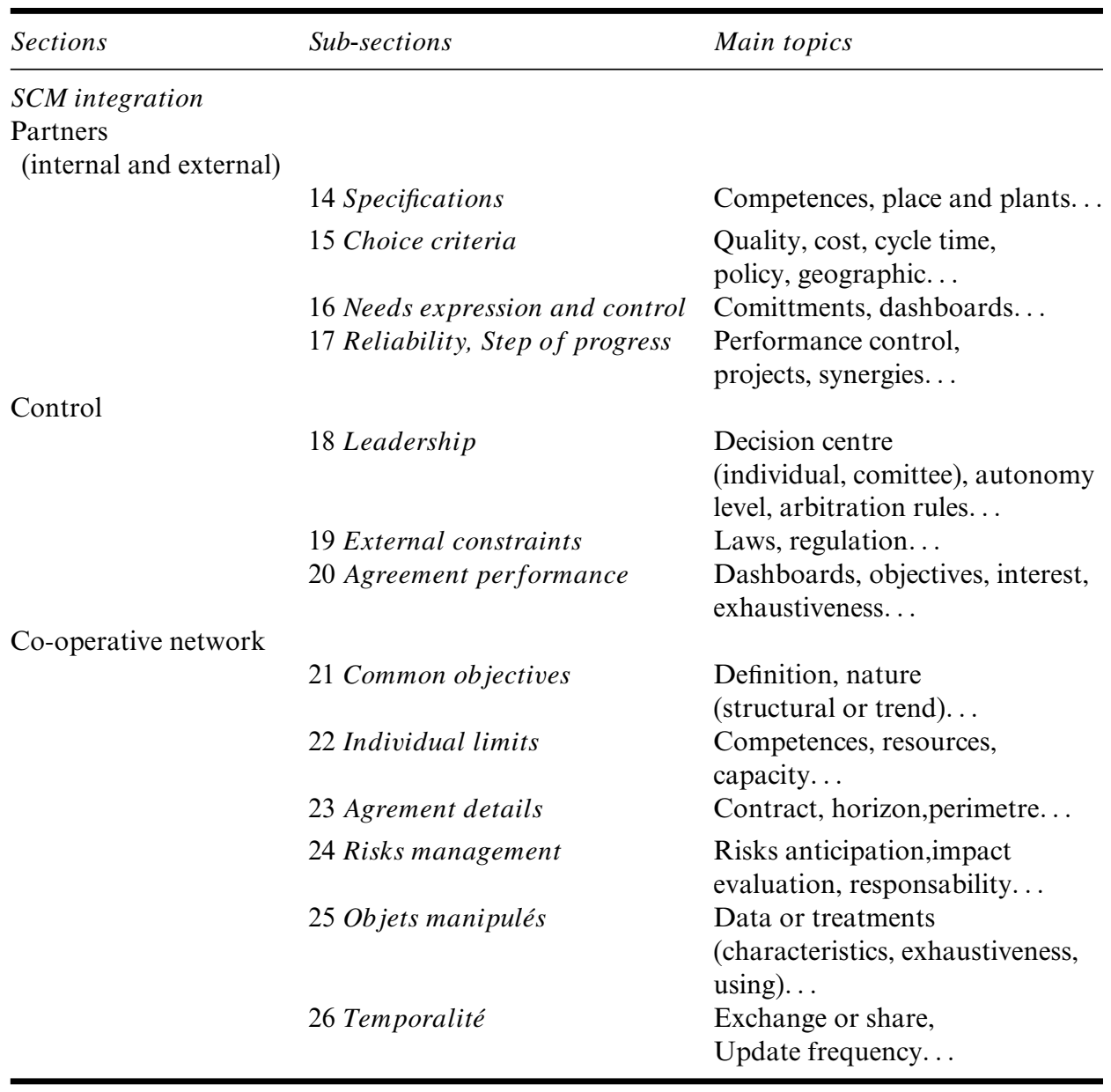

\subsection{Elements of theory for data analysis}

Several methods of data analysis are available (Bryman and Hardy, 2003). Into this set, the statistical exploratory or descriptive subset of methods is appropriate to synthesise and summarise the information included in the data. Their role is to highlight the main features of an observed population and to suggest assumptions about their classification. We can divide the descriptive statistics into (Bouroche and Saporta, 1998; Bryman and Hardy, 2003):

- classification methods (to form groups of individuals)

- factorial methods (to reduce the number of characteristics)

- Principle Component Analysis (quantitative)

- Correspondence analysis (qualitative)

- Canonical analysis (bond between characters) 
Here, we aim to create typologies of individuals (taxonomy of entities) starting from an observation of the population by a whole set of characters (variables that are answers collected during the investigation), trying to answer the question of whether they are similar or different. Our study clearly requires factorial methods. The art then consists in controlling a compromise between a model of data representation (based on linear correlation between pairs of characters) and the values of the data themselves. The Principle Component Analysis (PCA) and the Multiple Correspondence Analysis (MCA) are two complementary factorial methods that can be applied. The PCA treats the quantitative variables, while the MCA treats the qualitative variables.

Figure 1 Global architecture for a relevant SCM diagnosis (see online version for colours)

Framework for SCM diagnosis

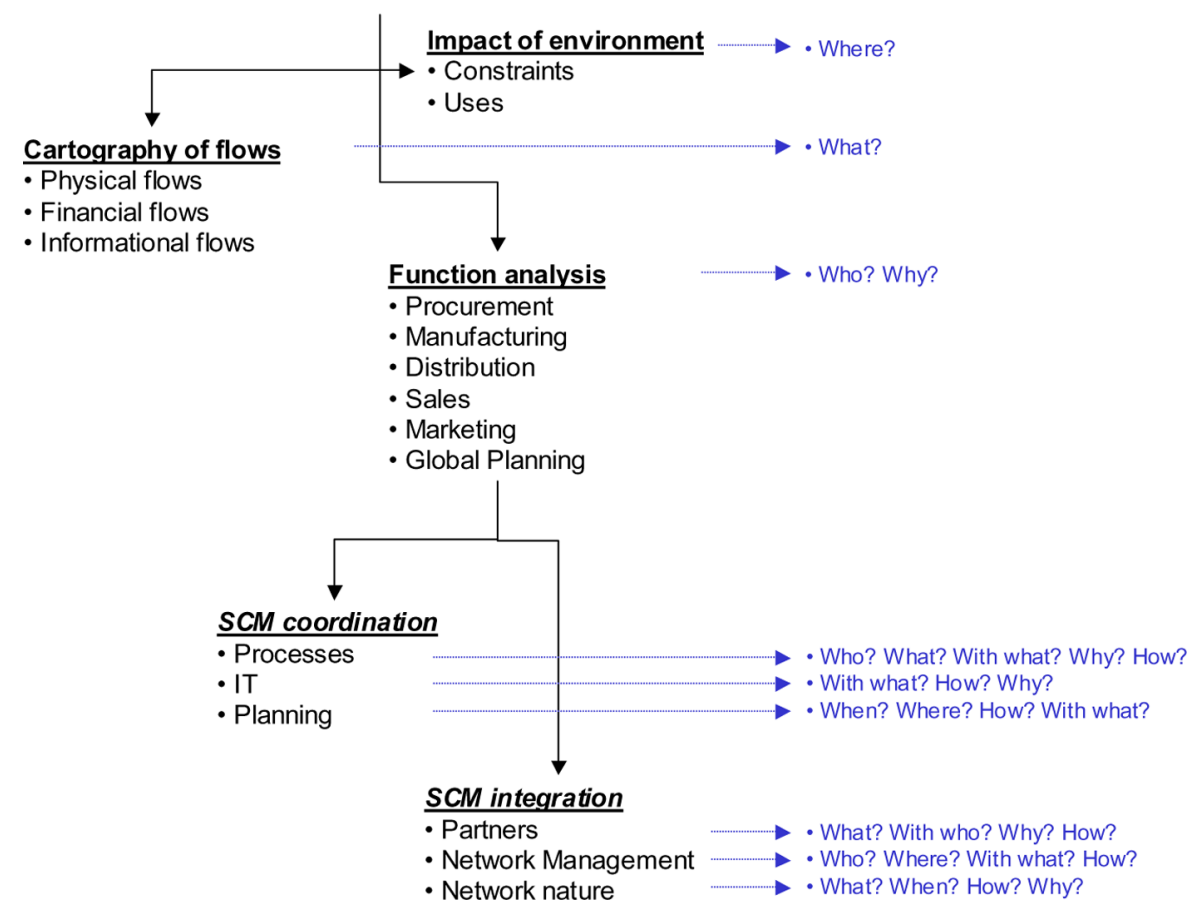

\subsection{Global approach}

On this basis, we develop an approach in four steps (Lauras et al., 2006) (Figure 2):

1 Analysing the internal processing modes of each entity in order to select the entities that have the same local characteristics. We want to know which entities behave similarly locally. As the nature of the data must be taken into account, the analysis is broken down into three phases:

a First an analysis is made on the quantitative elements using a Principle Component Analysis (PCA). This highlights key quantitative variables that explain the major quantitative differences between the entities (effect of scale in particular). 
b Then a Multiple Correspondence Analysis (MCA) is carried out to analyse the qualitative characteristics by function. Key qualitative variables are thus obtained by function.

c Finally, a global analysis is performed on all the key variables of the entities. It enables us to define global classes of entities. It also enables us to measure which are the functions or quantitative elements that mainly explain the differences between classes. This is relevant only if a big enough ratio of the initial data is expressed in the final categories.

The questions are: Are all these categories necessary? Should management standardise local processes of the entities involved in a given category?

Are the classes obtained at phase 1.c coherent with those obtained per function at step 1.b?

Figure 2 Global methodology to identify typologies (see online version for colours)

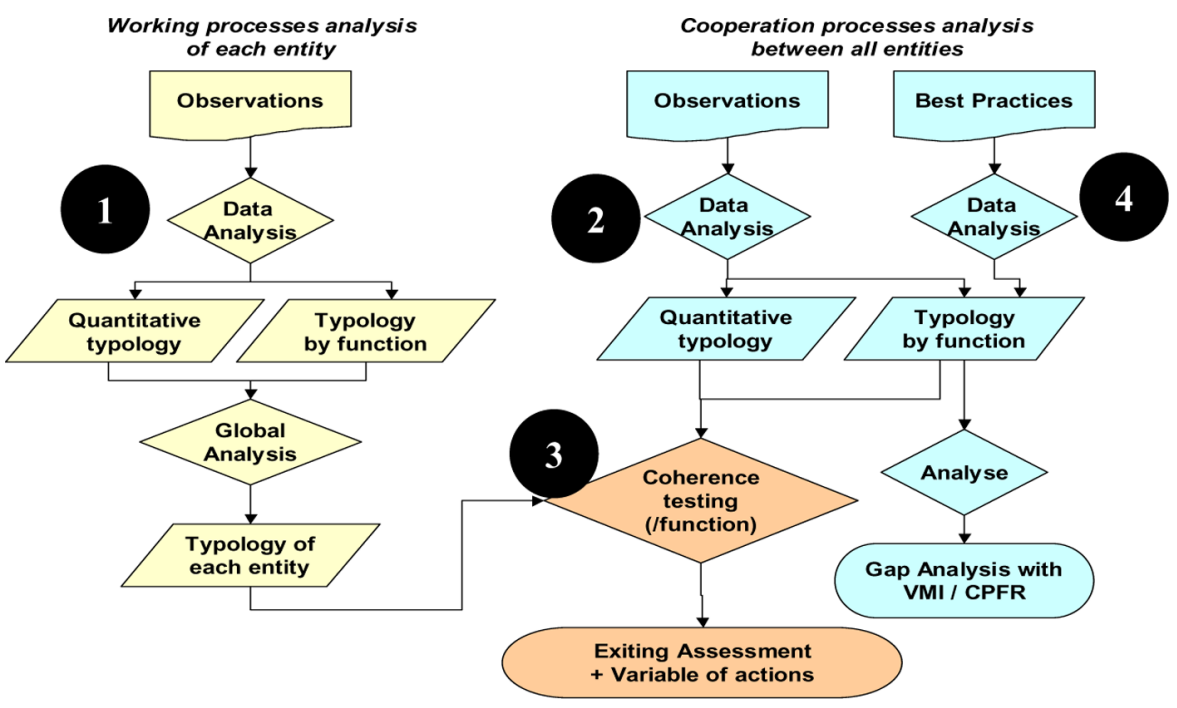

2 Analysing the cooperative agreements existing between entities. Here the idea is to define typologies of cooperation. Here the analysis is broken down into three phases in the same way as step 1 .

3 Checking whether the agreements are coherent with typologies of local processes: The logical assumption is that a series of individuals of the same category, therefore having the same local characteristics, should be found in the same cooperation class.

A test of coherence crossing typologies of local processes and typologies of cooperation identify the variations with respect to this assumption. If the typologies have poor similarities, this leads to a great diversity in the modes of management. Here the management should decide which are the relevant collaborative processes for each class of local entities.

This coherence test can also be carried out per function. The relevance of doing this is twofold: 
- On the one hand, less information is lost as the comparison is made on the results of the $1 . b$ and $2 . b$ analysis

- On the other hand, global incoherence can result from entities being gathered into classes that differ from one function to another. Therefore, the test by function shows the source of incoherence more precisely. Finally some complementary investigations can be made to explain incoherence, and to determine the improvement projects that can solve it.

4 From the literature on the subject, identifying 'best practices' cooperative processes. So, virtual entities are qualitatively characterised according to these 'best practices'. Then, step 2.b and 2.c are performed again. This enables us to identify key variables that mainly explain the distance between actual cooperative agreements and 'best practices': they are the characteristics to be modified in order to converge to the best practices.

Finally, from a manager point of view, the interest for this approach is twofold: first, it enables to define classes of entities so that the management can be adapted per class. Secondly, key variables are identified that define these classes: they are the characteristics that have to be changed in order to move an entity from a class to another.

Now as time passes, the supply chain evolves: entities local or cooperative characteristics change, new entities appear, others disappears. In this situation, two cases are supported by the data analysis approach:

- The complete methodology applied once again. This is long and costly as all the data must be collected again or even actualised. But it provides a guarantee on the representation of the chain.

- Key variables, as identified at steps 1.a, 1.b, 2.a, 2.b are assumed to be the same, even if entities' value change for them. Here a simple questionnaire restricted to questions to the key variables. It enables a quick and efficient gathering of the data. But only the 1.c, 2.c and 4.c analysis can be obtained.

Moreover, in both cases, managers can be interested to compare analysis at different dates. As data change, PCA and MCA made for different dates may result in changes in axes definition. In this situation, the manager should choose the axes definition of a given date and project all the entities evaluation (new and old ones) on these axes. Here the risk is that the projection loses a lot of information, if the supply chain key variables have changed drastically from on date to another.

\section{A pharmaceutical and cosmetic supply chain case study}

Application is dedicated to a pharmaceutical and cosmetic company and has been performed in collaboration with its supply chain department. The supply chain management asked for a diagnosis of the cooperation between the manufacturing plants (central entity) and the distribution system in the foreign countries (Figure 3).

All the analyses led on the application case cannot be presented here. Nevertheless, two illustrative analyses will be developed in the following: 
- quantitative data on local processes of distributors: physical flow analysis (PCA results for step 1.a)

- qualitative data on cooperation processes: gap analysis with VMI and CPFR best practices (MCA results for step 4.c).

Figure 3 The supply chain under study (see online version for colours)

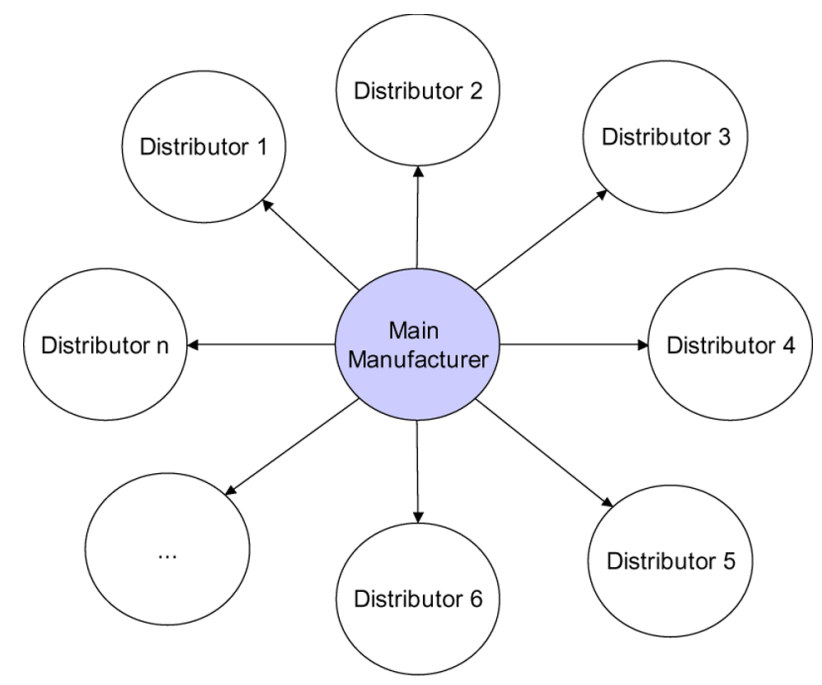

\subsection{From the framework to the questionnaire}

A preliminary investigation was carried out with the central entity to prepare the meeting with distributors, on the basis of our reference framework for diagnosis. We particularly focused on Distribution (Manufacturer), Procurement (Distributors), and Global Planning functions. The Sales, Marketing and Manufacture functions will be less detailed.

This phase consisted in some contact actors from Quality Management, Sales Administration, Distribution, Legislation, Supply Chain, Data-processing. A set of 120 questions have been made up to cover 300 topics of the reference framework (a question can inform several aspects of the system studied). These 300 topics were identified after reducing the framework by omitting irrelevant sections (Lauras, 2004). For obvious confidentiality reasons, we are not able to reveal here the exact contents of these questions. We can nevertheless give key points that have to be observed throughout the questionnaire:

- Questions about Flows: What is the inventory value (final products and promotional articles)? How many units (weights, volumes, containers)?

How many dataprocessing users are used? How many customers (by type)?

- Questions about Distribution: How is the activity of distribution scheduled? Which kind of contract has been subscribed to by customers (inductors of costs, duration)? What are the delivery cycle times (targets and noted)?

- Questions about Procurement: which methods and which tools are used for the procurement planning? What is the frequency of the head office's deliveries? 
- Questions about Global Planning: How are forecasts established? Which dashboard is set up to follow the activity?

- Questions about Production: What is the process of complementary packaging (activity, means, instructions, inputs/outputs, performance)?

- Questions about Marketing: Are there, locally, created promotional articles? Which brands are marketed?

- Questions about Sales: What are the various types of orders (specificity)? What is the organisation of the sales networks?

\subsection{Investigation}

Our investigation focused on twelve European distributors and their main manufacturer, to acquire a knowledge of the companies, theirs organisations, cultures and operations.

For each distributor, an on-site mission lasting three days enabled us to collect precise and exhaustive qualitative data: interviews with local managers of each function and of their correspondent at the central entity. We also extracted, from the local databases, the inputs and outputs of each distributor in order to detail a physical and informational cartography of flows (dynamic). Additional quantitative information (static and financial informational flows) was obtained at the same time from the local financial control managers. The rate of reply to the survey exceeded $85 \%$. From the elements collected, we retained 147 explanatory characters of the local processes, and 143 explanatory characters of the cooperation processes implemented between the central entity and its distributors.

\subsection{Example of local processes analysis: quantitative flows-PCA method}

A PCA was first carried out on the totality of the numeric variables relating to physical and informational flows ( 12 individuals and 26 characters). The characters under study are mainly references, orders, lines of orders, types of parcels/pallets, inventory levels, manpower, number of sales networks, number of customers as well as seasonally ratios. We can see from the start that two axes represent more than $85 \%$ of the information (Table 4). This allows us to interpret the results accurately and reliably.

The first axis shows that the following volumetric data move in the same direction: orders, multi-reference parcels, backorders, lines of orders, stocks, references, units, picking operations and numbers of commercial networks. It thus appears that the main part of the orders is characterised by flows of 'detail' (parcel multi-references, picking operations). We also note that no character is opposed to this tendency. This last very significant point underlines the fact that any increase in volume on an unspecified criterion automatically generates increases in the same proportions in the other inductors. For the next step of our analysis, the use of only one variable among these will be sufficient (we will call it 'detail flow').

The second axis shows that the other type of orders which are characterised by flows known as 'complete' (complete parcels, complete pallets), are linked together and move in the same direction. It is nevertheless necessary to counter balance this assertion by the low representativeness of this axis (vs. axis 1). The concepts of seasonality and a number of references are opposed. We can explain this point as large volumes are generally 
related to pharmaceutical products intended for wholesalers, whereas volumes of 'details' are related to cosmetic products for retailers. This last activity is mainly based on seasonal products (solar, thinners for example). In addition, the cosmetic catalogue naturally includes many more references (promotions, innovations). This analysis shows that the activity of an entity can be divided into two distinct components: management of large volumes, and management of smaller volumes. Each component is the consequence of the local market structure.

Table 4 Axes signification - PCA analysis - physical and informational flows

\begin{tabular}{|c|c|c|c|c|}
\hline & Axe 1 & & Axe 2 & \\
\hline & $74.3 \%$ & & $12.5 \%$ & \\
\hline \multirow[t]{11}{*}{ Positive contributions } & Orders & $6 \%$ & Complete pallets & $24 \%$ \\
\hline & Multi-references parcels & $6 \%$ & Complete parcels & $11 \%$ \\
\hline & Shipments & $6 \%$ & Manpower & $7 \%$ \\
\hline & Order lines & $6 \%$ & & \\
\hline & Active inventory & $6 \%$ & & \\
\hline & Safety stock & $6 \%$ & & \\
\hline & References & $5 \%$ & & \\
\hline & Units & $5 \%$ & & \\
\hline & Picking references & $5 \%$ & & \\
\hline & Picking operations & $5 \%$ & & \\
\hline & Commercial networks & $5 \%$ & & \\
\hline \multirow[t]{3}{*}{ Negative contributions } & & & Inventory seasonality & $-10 \%$ \\
\hline & & & References & $-5 \%$ \\
\hline & & & Shipment seasonality & $-5 \%$ \\
\hline
\end{tabular}

From this PCA, we can define four classes (Figure 4):

- the pharmaceutical distributors: 2, 4, 9 and 12 as well as the homeopathic distributors 5 and 10

- the cosmetic distributors: 6 and 8

- the cosmetic distributors: 1,3 and 11

- $\quad$ the pharmaceutical distributor 7.

It can be stated that unlike other distributors, the pharmaceutical distributor 7 shares an activity between two types of identified flows. Distributor 7, indeed, also supports the marketing of family medication products (i.e., those one which are naturally close to cosmetics) for its country. In all the other countries, this activity is controlled by cosmetic distributors. Moreover, cosmetic distributors 6 and 8 can be distinguished from the others by the much greater volumes that they deal with.

\subsection{Data analysis of the cooperative distribution processes flows: qualitative elements - MCA method}

From step 1, 15 macro-characters representative of the distributor local processes have been obtained. 
At the same time, step 2 highlighted 12 macro-characters representative of the cooperation processes: 3 resulting from the PCA are carried out on the quantitative characters [type of transport ratio, product specificity ratio, volumes], 2 relate to the 'marketing' function [new product development, co-marketing], 4 relate to supply chain planning [interoperability of tools, flexibility, performance in service rate and absolute value] and 3 relate to the supply chain execution [costs, reception capacities, transportation cycle time]. These steps also result in a taxonomy of the local and cooperative processes.

Figure 4 Factorial plan - PCA analysis - physical and informational flows (see online version for colours)

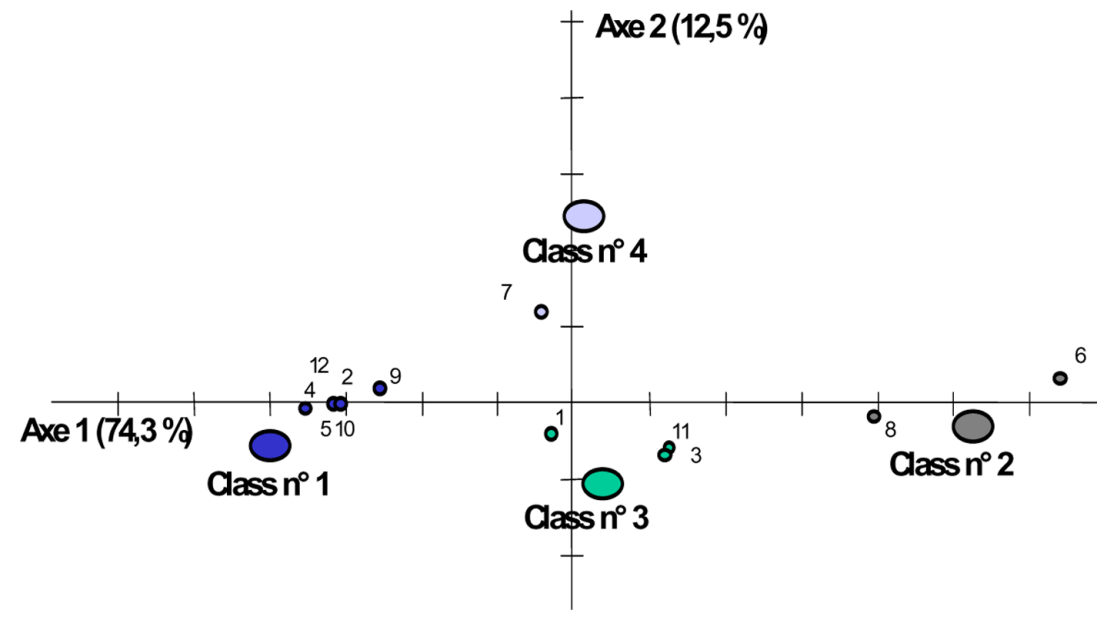

The test of coherence (step 3), on each function, regarding different classes of cooperation agreements, and those of local processes, revealed that: cooperation processes on marketing, sales, and supply chain planning functions were coherent with the local distributor classes, while distribution execution and supplying functions were not. This enabled us to focus specific investigations on these functions for the distributors that were at the source of these incoherencies.

On the basis of research on cooperative processes in supply chains (Aviv, 2001; Dudek and Stadtler, 2004), we develop here step 4 of our approach. Articles which review cooperation techniques (Martin, 1995; Seifert, 2003) stress that the main concepts used by companies of nowadays is the ECR and its principal tools. We thus sought to locate the existing cooperative agreements in relation to these concepts. We consequently created two distributors artificially (VMI (subsidiary $n^{\circ} 13$ ) and CPFR (subsidiary $\left.n^{\circ} 14\right)$ ) whose elementary character values were estimated by accordance with best practices. Step 2 of the approach was launched again.

The analysis in Figure 5 relates to twelve observations: real observations (except the two homeopathic distributors) and two fictive observations. On its positive part, axis 1 characterises cooperation agreements based on sharing data and/or treatments. It highlights the tools used within the framework of these relations (MRPII integration, common coding, integrated information systems). Negative contributions highlight the existence of agreement processes that are not formalised or are not supported by structured information systems or processes. They are 'in communication' or 'in collaboration' states. 
Figure 5 Factorial plan - MCA analysis - agreement processes (see online version for colours)

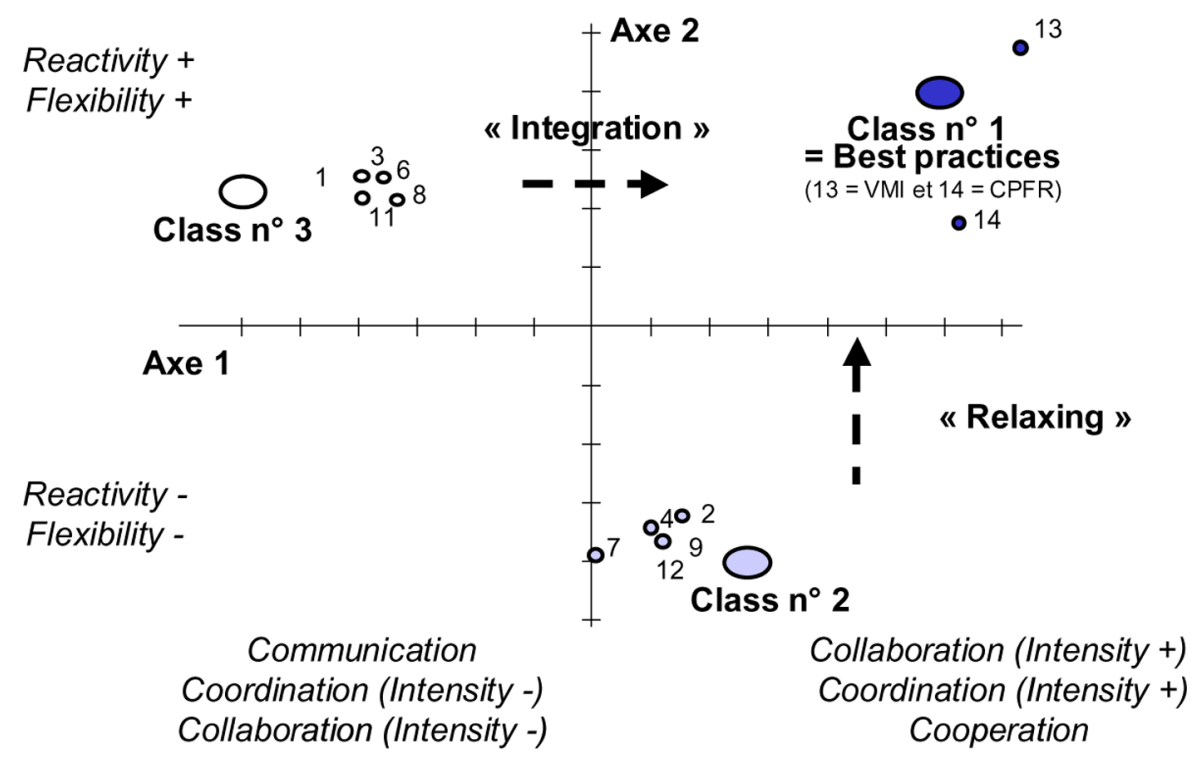

In its positive part, axis 2 puts forward some very reactive and flexible systems (short frozen planning horizons, weekly meetings, unit orders, small integrated information systems). Less reactive and flexible systems (long frozen planning horizon, highly integrated information systems, large order lots) are characterised by negative contributions.

The MCA distinguishes two groups of individuals in terms of their relationship to the head office, in terms of best practices (class 1):

- observations of class 2 (agreements with pharmaceutical distributors), although already subject to collaboration and cooperation, must relax their processes in order to gain flexibility and reactivity

- observations of class 3 (agreements with cosmetic distributors) must progress from a simple state of agreement (elementary communication, coordination or collaboration) to a more complete state (advanced cooperation, coordination or collaboration), while still preserving the qualities of reactivity and flexibility which characterise them today.

\subsection{Conclusion on the application}

Our proposal helped the supply chain managers in three ways:

- The reference framework enabled them to be confident in the quality of the questionnaire

- The analysis on the collected data enabled them to figure out the state of their SCM 
- The comparison with VMI and CPFR processes enabled them to identify differences and what could be changed. But, it did not enable them to evaluate potential added value. This last evaluation still relies on the management interpretation.

\section{Conclusion}

Some gaps in knowledge and in methodologies which are used to investigate supply chains have been identified. This paper proposes a solution to progress in SCM diagnosis. It includes two main components:

- a structured reference framework for collecting the data that explain the mechanisms of given SCM processes and particularly collaborative processes

- $\quad$ an approach, based on data analysis tools (PCA and MCA), to extract and analyse relevant information included in those data in a given SC architecture.

The object of this methodology is to structure the diagnosis step and thereby prepare the next phases of a continuous improvement step for supply chain processes. It makes it possible to structure, understand and exploit the awareness and weakness of supply chain entities and supply chain interactions.

The relationships between a pharmaceutical and cosmetical product manufacturer (central entity) and its European infrastructure of distribution services (a set of national entities) have been focused on. The proposed diagnosis appears to be useful and enables the definition of progressive improvement in the standardisation of some distribution local processes and also in the cooperation agreements with the central entity.

Several questions arose, which still need to be answered:

- Can management accept divergences between taxonomies of agreements and those of local processes?

- Is it necessary to privilege certain states of agreements?

- Should the 'actual' states of agreements systematically develop into the best practices?

- How we can develop an 'a priori' use of our proposal in order to identify the various trajectories of evolution?

Besides, a significant piece of information is missing to answer these questions: performance evaluation has been addressed in other related papers by the same authors (Lauras, 2004; Lauras et al., 2005).

\section{References}

Arnold, T. and Chapman, S.N. (2004) Introduction to Material Management, 5th ed., Prentice-Hall.

Aviv, Y. (2001) 'The effect of collaborative forecasting on supply chain performance', Management Science, Vol. 47, No. 10, pp.1326-1343. 
Beamon, B.M. (1999) 'Measuring supply chain performance', International Journal of Operations and Production Management, Vol. 19, No. 3, pp.275-292.

Benton, W.C. and Maloni, M. (2005) 'The influence of power driven buyer/seller relationships on supply chain satisfaction', Journal of Operations Management, No. 23, pp.1-22.

Bouroche, J.M. and Saporta, G. (1998) L'analyse des données, Presses Universitaires de France.

Bryman, A.E. and Hardy, M.A. (2003) Handbook of Data Analysis. Sage publications.

Cachon, G.P. and Fisher, M. (2000) 'Supply chain inventory management and the value of shared information', Management Science, Vol. 46, No. 8, pp.1032-1048.

Chen, I.J. and Paulraj, A. (2004) 'Towards a theory of supply chain management: the constructs and measurements', Journal of Operations Management, No. 22, pp.119-150.

Chopra, S. and Meindl, P. (2003) Supply Chain Management, 2nd ed., Prentice-Hall, p.457.

Chronéer, D. (2004) 'The impact of supply chain information and networking on product development in Swedish process industry', International Journal of Logistics Systems and Management, Vol. 1, Nos. 2-3, pp.127-148.

Cooper, M.C. and Ellram, L.M. (1991) 'Characteristics of supply chain management and the implications for purchasing and logistics strategy', International Journal of Logistics Management, No. 4, pp.13-24.

Croxton, K.L., Garcia-Dastugue, S.J., Lambert, D.M. and Rogers, D.S. (2001) 'The supply chain management processes', International Journal of Logistics Management, Vol. 12, No. 2, pp.13-36.

Dudek, G. (2004) Collaborative Planning in Supply Chains: A Negotiation Based Approach, Springer Verlag, p.234.

Dudek, G. and Stadtler, H. (2004) 'Negotiation-based collaborative planning between supply chain partners', European Journal of Operation Research, Vol. 163, No. 3, pp.668-687.

Ellram, L.M. (1991) 'Supply chain management: the industrial organization perspective', International Journal of Physical Distribution and Logistics Management, No. 21, pp.13-22.

Gunasekaran, A., Patel, C. and McGaughey, R.E. (2004) 'A framework for supply chain performance measurement', International Journal of Production Economics, No. 87, pp.333-347.

Hammer, M. and Champy, J. (1993) Re-engineering the Corporation, Harper Business.

Handfield, R.B. and Nichols, E.L. (2002) Supply Chain Redesign: Transforming Supply Chains into Integrated Value Systems, Prentice-Hall, p.371.

Heikkila, J. (2002) 'From supply chain management: efficiency and customer satisfaction', Journal of Operations Management, No. 20, pp.747-767.

Kearney, A.T. (1994) Management Approach to Supply Chain Integration, Internal Research Report, Chicago.

Lauras, M. (2004) Méthodes de diagnostic et d'évaluation de performance pour la gestion de chaînes logistiques, PhD Thesis, Institut National Polytechnique de Toulouse, p.192.

Lauras, M., Pingaud, H. and Lamothe, J. (2005) 'Performance evaluation of supply chain processes according to determinants', 1st International Conference on Operations and Supply Chain Management, Bali-Indonesia, 17-19 December, pp.9-16, ISBN: 979-545-0395.

Lauras, M., Pingaud, H. and Lamothe, J. (2006) 'An approach to define local and cooperative typologies of supply chain processes', International Conference on Information Systems, Logistics and Supply Chain, Lyon-France, 15-17 May, ISBN: 2-930294-18-3.

Lee, H.L., So, K.C. and Tang, C.S. (2000) 'The value of information sharing in a two-level supply chain', Management Science, Vol. 46, No. 5, pp.626-643. 
Manthou, V., Folinas, D. and Vlachopoulou, M. (2005) 'Establishing an integrated virtual logistics network', International Journal of Logistics Systems and Management, Vol. 1, No. 4, pp.354-365.

Martin, A.J. (1995) Infopartnering: The Ultimate Strategy for Achieving Efficient Consumer Response, John Wiley \& Sons.

Mentzer, J.T., Dewitt, W., Keeber, J.S., Min, S., Nix, N.W., Smith, C.D. and Zacharia, Z.G. (2001) 'Defining the supply chain management', Journal of Business Logistics, Vol. 22, No. 2.

Palmer, J.W. and Griffith, D.A. (1998) 'Information intensity: a paradigm for understanding web site design', Journal of Marketing Theory and Practice, No. 6, pp.28-42.

Poirier, C.C. and Reiter, S.E. (1996) Supply Chain Optimization: Building the Strongest Total Business Network, Berret-Koehler Publishers, Inc., San Francisco.

Rigatto, P., Padula, A.D. and Larson, D.W. (2005) 'Difference between supply chain structures within a given industry: insights from the Brazilian peach canning industry', International Journal of Logistics Systems and Management, Vol. 1, No. 4, pp.311-330.

Seifert, D. (2003) 'Collaborative planning, forecasting and replenishment: How to create a supply chain advantage?', American Management Association, p.375.

Simchi-Levi, D., Kaminsky, P. and Simchi-Levi, E. (2003) Designing and Managing the Supply Chain, International Edition McGraw-Hill, 2nd ed., p.354.

Stadtler, H. (2005) 'Supply chain management and advanced planning: basics, overview and challenges', European Journal of Operational Research, Vol. 163, No. 3, pp.575-588.

Stadtler, H. and Kilger, C. (2000) Supply Chain Management and Advanced Planning, Edition Springer-Verlag, p.371.

Supply Chain Council (2004) Supply Chain Operations Reference-Models - SCOR version 6.0., Edition Supply Chain Council, p.214.

Upton, D.M. and McAfee, A.P. (2000) 'A path-based approach to information technology in manufacturing', International Journal of Technology Management, Vol. 20, Nos. 3-4, pp.354-372.

Vickery, S.K., Jayaram, J., Droge, C. and Calantone, R. (2003) 'The effects of an integrative supply chain strategy on customer service and financial performance: an analysis of direct versus indirect relationships', Journal of Operations Management, No. 21, pp.523-539.

Villareal, C., Dupont, L., Gourc, D. and Pingaud, H. (2005) 'Understanding and managing shared projects in SMEs networks', 6th IFIP Working Conference on Virtual Enterprises, Valencia, Spain.

Williamson, O.E. (1985) The Economic Institutions of Capitalism, The free press, New York. 